\title{
The Importance of High-Quality Russian Language Services
}

\author{
Xi Zhang* \\ Heilongjiang Institute of Technology Foreign Language School, Harbin 150050, Heilongjiang Province, China \\ *Corresponding author: Xi Zhang, jessie_xixi@163.com \\ Copyright: ( $) 2022$ Author(s). This is an open-access article distributed under the terms of the Creative Commons Attribution License (CC \\ BY 4.0), permitting distribution and reproduction in any medium, provided the original work is cited.
}

\begin{abstract}
High-level opening up" and "high-quality development" are important development goals and directions of China during the 14th Five-Year Plan period. Heilongjiang, as the largest and oldest province open to Russia, has a long history of communication and plays a vanguard role. However, the province's geographical advantages are weakening under the impact of the COVID-19 pandemic and the rapid development of the internet industry. Facing the new era, maintaining and enhancing the regional advantages of the province has become an urgent issue that requires attention. This study takes the Russian language service in Heilongjiang Province as the subject, combines theory with practice through theoretical elaboration and historical analysis, as well as tries to provide reference for improving the language service system in Heilongjiang Province and enhancing its regional advantages. This study believes that a high-quality language service plays an important role in solving the issue. It is necessary to fully understand and apply the essential power of language, be more aware of the importance of Russian language services, build a sound ecosystem of language services, give full play to the traditional advantages of the "Russian" in this province, and finally assume "Russian language services" as the "golden banner" for the development of language services, economy, and culture in the province.
\end{abstract}

Keywords: Language service; High quality Russian language services; Regional advantages; Ecosystem of language services

Online publication: January 24, 2022

\section{Introduction}

In October 2020, the Fifth Plenary Session of the 19th Central Committee of the Communist Party of China (CPC) accepted the proposal for formulating the 14th Five-Year Plan for National Economic and Social Development and the Long-Term Goals for 2035. It is pointed out in the proposal that during the 14th FiveYear Plan period, China will carry out high-level opening-up, continue to carry out wider and deeper opening-up, as well as promote high-quality cooperation. As the largest province of opening-up and cooperation with Russia, Heilongjiang has correspondingly put forward suggestions to comprehensively improve the carrying capacity of cooperation with Russia. It is not hard to appreciate that "high quality" is an important keyword in the 14th Five-Year Plan period.

Heilongjiang Province, as a pioneer in trade with Russia, has great historical and geographical advantages. However, the impact of COVID-19 has been far-reaching, and the internet industry is growing rapidly. It is imperative to figure out how to maintain and enhance the regional advantages of the province, especially under the background of the new era when its geographical advantages are gradually weakening. High-quality services, especially language services, have become important supports in solving this issue.

As an intermediary, language plays a crucial role in the mutual cognition and communication between China and Russia. The reason why Russian language can play such a significant role is associated with the 
essential power of the language itself.

\section{The power of language - the use of "dialogue" to build a united, consistent, and friendly community}

Language is a mysterious existence. It does not only clarify the nature of the world, but also drive the integration of people. Through "dialogue," people come to terms with the world and transform it; in this process, they gain enlightenment and promotion. Therefore, language has practical meaning. It is the practical significance and reality of language that makes "Russian" open a new door of understanding and reflection for people as well as enable China and Russia to cooperate through "dialogue."

Language, since its appearance, is with a strong mysterious color. Language has been viewed with superstitious eyes for as long as people have been able to record thoughts ${ }^{[1]}$. In ancient Greece, language, reason, and law were the same word; in the Bible, language and the beginning of the world are one. This unexplainable mystery has not stopped people from searching for the nature of language. Since modern times, many linguists and philosophers have defined language from the perspective of experience. The German philosopher Gadamer once said, "Being that can be understood is language ${ }^{[2]}$." It can be seen that Gadamer's philosophical hermeneutics pays more attention to the relationship between language and meaning.

In Gadamer's opinion, language provides a way for human activities to be understood in context and to guide life practice. Language is the way of human existence. People experience the world through language, which is the image representation of the world. People see the unity between the finitude of things shown and the infinity of things not shown in the mirror image. This implies the unity of what is said in language and the infinite possibilities that remain unsaid. Therefore, in Gadamer's hermeneutic vision, language is a speculative language. There is a dialogical logic in language dialectics; that is, the questionand-answer dialectic. This dialectic is the art of leading dialogue and the basic structure of dialogue. People's awareness of their own ignorance and thirst for knowledge are motives for questioning. In the question-and-answer process, the participants of the dialogue put forward questions and provide answers fairly and equally. The negligence of a certain aspect presupposes the context and scope of the question, and the answer reflects a form of uncertainty and openness in the preset scope. This kind of open answer leads to new questions, and dialogue shows the logic of objectivity by leading the development of thoughts through continuous questioning without leading opinions. In this way, a person has some connection with the world and others through language. Through this process, people would come to know the world and other people, reflect on themselves, and achieve the meaning of living. At the same time, a new concept of the world and others would be formed, and the experience of "me" would improve to conform to this new concept, so as to improve oneself and reach self-enlightenment.

Language carries practical wisdom, instructing people on how to deal with problems in life. Gadamer uses "dialogue" to link social reason with understanding. Proceeding from reason, it is necessary to build a community of unity and friendship through dialogue ${ }^{[3]}$. The community of "dialogue" should not be a "monologue" community, but a human community that embraces diversity and alienation - "harmony without uniformity." "Dialogue," in essence, is a civilized way of understanding. People come to know the world, others, and themselves through language and dialogue. In this process of enlightenment, people experience the world and merge their horizons. When people acquire world experience, the world also changes because of dialogue. Therefore, language has more social and ethical enlightenment significance. In cooperative communication, human beings use language to initiate, preserve, modify, and act on all aspects of morality by forming common commitment and teaching norms, changing social reality, providing moral reason, and so on ${ }^{[4]}$. In other words, it is through language that one can accurately understand one's own value and the value of others. It is through "dialogue" that one can cultivate friendships with other nations, establish norms for exchanges and cooperation, reach basic agreement in 
terms of goals, as well as build a community with a shared future for mankind, which is fair, good-will, peaceful, and win-win.

\section{Historical relationship between Russian language services and the regional development in Heilongjiang Province}

Macroscopically speaking, language plays an indelible role in the self-interpretation of human beings, the understanding of world experience, and the development of human destiny. From the micro point of view, specifically on how to improve the geographical advantages of the province, language (especially Russian) should also assume its responsibilities and play a positive role. Russian language services, especially the cultivation of Russian talents, are closely related to the economic development, trade, culture, and other aspects of cooperation between Heilongjiang and Russia.

The Russian language education in Heilongjiang Province began during the Qing Dynasty. After the signing of the Treaty of Nerchinsk between China and Russia, there have been frequent trades between those two countries. In order to meet the needs of communication between the two countries, in the 22nd year of Guangxu (1896), Heilongjiang's general, Enze Sabao, established the Heilongjiang Russian School, marking the beginning of Russian education in Heilongjiang ${ }^{[5]}$.

As the first socialist country in the history of the world, Soviet Union carries valuable experiences worth learning. Therefore, before the founding of New China, Harbin established a foreign language school affiliated to the General Headquarters of the Northeast National Coalition forces (later renamed as Harbin Institute of Foreign Languages) to train Russian talents needed for the revolutionary struggle and national construction at that time. In August 1949, the Northeast Bureau of the CPC Central Committee and the Northeast Administrative Committee issued the Decision on the Reorganization of Higher Education, stipulating that Harbin Institute of Foreign Languages should be an institution of higher learning for the cultivation and training of Russian translation talents in the northeast and that Russian should be the first foreign language ${ }^{[6]}$. Harbin Institute of Foreign Languages has laid a solid foundation for Russian education after the founding of New China in terms of Russian teaching, teaching staffs, and training of Russian talents.

The excellent teaching tradition of Russian in the province is not only reflected in the training of specialized talents, but also in its basic education. In the 1950s, China set off an upsurge to learn from the Soviet Union. In 1950, The Interim Teaching Plan for Middle Schools (Draft), which is a teaching plan promulgated by China, proposed that Russian should be set as the main curriculum of foreign languages in middle schools ${ }^{[6]}$. The Russian language has become the preferred foreign language for basic education in many cities in Heilongjiang Province. Most of the older generation, born in the 1930s and 1940s, do not speak English, but instead, they are familiar with a few simple Russian words. Therefore, it is not difficult to appreciate the prosperity and popularity of the Russian language at that time. In Heilongjiang Province, Russian is far superior to English in terms of the enthusiasm for learning among teachers and students. In view of the flourishing of Russian-speaking talents, Heilongjiang has become the center of cultural exchanges with Russia, thus promoting the prosperity of Chinese-Russian cultural exchanges. At that time, a large number of Russian and Soviet literary works were translated in Heilongjiang and were deeply loved by the Chinese people. Most of the outstanding Russian literature translators are from Heilongjiang or have worked or studied in Heilongjiang ${ }^{[7]}$.

After the implementation of the policy for the reform and opening-up, the trade between Heilongjiang Province and Soviet Union soared, and the border trade between Heilongjiang Province and the Far East of the Soviet Union recovered. In the 1980s, a second "Russian fever" occurred. In many areas of Heilongjiang Province, Russian was the first choice in foreign language learning. It did not only provide a large number of Russian professionals for the development of the country at that time, but also help gathered Russian 
teaching experience and excellent teachers for Russian education in Heilongjiang. Culturally, translated literature in Heilongjiang is flourishing. The translation of Russian and Soviet literary works leads the way. A large number of Russian and Soviet literary works published on the market are mostly translated by the people from Heilongjiang.

In the 1990s, influenced by the disintegration of Soviet Union, the popularity of English, and the widespread use of computers as well as the internet, the Russian education in several schools in Heilongjiang declined and reached a low ebb; some schools even removed the Russian course. During the same period, Heilongjiang-Soviet trade officially became known as Heilongjiang-Russia trade and experienced a slow recovery from that low ebb. In the beginning of this century, with the establishment of a new cooperative relationship between China and Russia, there were more demands for Russian talents in various fields in China. The Russian education in Heilongjiang gradually restored, some middle schools resumed the Russian curriculum, and many middle schools added the Russian curriculum ${ }^{[6]}$.

In the 21 st century, China-Russia trade entered a stage of strategic upgrading, shifting from barter trade, which relies on border ports, to cross-border e-commerce trade. The content of trade cooperation has also changed from daily necessities to strategic cooperation in energy, science, technology, and education ${ }^{[8]}$. In 2017, Heilongjiang Province also entered a new era of trade development with Russia. This change led to the transformation of the Russian language service industry. The training mode of Russian talents has been reformed from simple language and translation teaching to "language + specialty" teaching. In the last two years, the demand for talents in language service has been on the rise. The national strategic needs and the regional development of the province have put forward higher requirements for the training of Russian talents. However, the current situation of the Russian language service in the province, especially in the cultivation of Russian talents, is not optimistic. The main reason lies in the shortage of Russian students. Although the students who study Russian in the province account for about two thirds of the students who study Russian in China, there is still a serious shortage of high-quality students. In regard to the college entrance examination held in 2003, there were less than 9,000 Russian candidates in the province, accounting for one-fifth of the examinees, falling below the historical lowest point ${ }^{[9]}$.

By comparing the history of Russian education in the province and the history of economic, trade, and cultural exchanges between the two countries, it is not difficult to appreciate that the origin, development, prosperity, and decline of language services, especially Russian language services, are related to the needs of regional development. In other words, Russian language services are in fact designed to meet the needs of China-Russia trades. At the same time, every boom in Russian education has greatly promoted the rapid development of the two countries. Although China and Russia have maintained friendly relations and continued to strengthen their cooperation in various aspects, these measures did not invigorate the current situation of the Russian services in the province. There is no expected "Russian fever" as there was in the 1950s and 1980s. The recruitment of Russian majors in universities in the province continues to be low, and Russian as a foreign language for the college entrance examination and foreign language students is even lower. Taking the enrollment of Russian language major in Northeast Petroleum University as an example, there were 16 Russian students in 2015, 15 in 2016, 5 in 2017, 15 in 2018, 15 in 2019, and 21 in 2020. Russian majors accounted for less than $0.5 \%$ of the total students in school. This proportion exposes the low recognition of the Russian language by students in the cultivation of higher talents in the province.

\section{Importance of strengthening personnel training and several feasible measures}

The national and regional development is in need for Russian service talents, which however lags behind in providing high-quality and large-scale language services. This inevitably leads to a lack of vitality in exchanges and cooperation with Russia. The high-quality language service system includes the cultivation of language service personnel and the construction of language service institutions as well as the language 
service environment, among which the core is the cultivation of Russian talents. Therefore, in order to fundamentally solve the lag, a benign ecological system of Russian language service should be established. The "Benign Ecological System of Russian Language Service" is a complete training system that includes Russian students from seeds (students) to seedling (teaching), to trees (practical training, talent exchange, and employment), and then to forest (Russian talent development system). This is not a closed loop of talent cultivation, but a virtuous spiral ecology. The adjustment of international environment and regional policy also has directional influence on language services. Therefore, the high-quality language service system should keep up with the pulse of the times as well as continue to reform and progress.

In order to build a high-quality language service system, it is essential to start from the source of students. By encouraging diversified development in high schools and making full use of the geographical advantages of the province, it is helpful to strengthen the input of Russian culture and cognition in the high school stage to build students' confidence and motivation for further learning. Second, it is also important to actively reform the teaching models, optimize the educational structure, discipline structure, and personnel training structure in such a way that they are compatible with the new development pattern, as well as promote the complementary of competitive disciplines. Since the current teaching model of "other professional major + Russian" is not practical enough ${ }^{[10]}$, the teaching model of "Russian major + other professional skills" is more feasible. Considering that some Russian majors have good English basis in high school, it is also beneficial to cultivate multilingual talents. Thirdly, it is imperative to make full use of the geographical advantages of the province and constantly strengthen exchanges with Russia, especially in the fields of culture and education, to provide students with a place to apply what they have learned so that their learning is purposeful and future oriented. Finally, the employment guidance and management of Russian service talents should be taken into consideration, so as to create a scientific management, sound system, as well as a stable and reliable foreign language service environment. Relevant government departments need to establish and improve corresponding policies and regulations. It is also advisable to encourage and support Russian service agencies to form school-enterprise cooperation with universities.

At present, there are universities offering Russian courses in all regions of the country. Compared with other regions, it is important to make full use of the geographical advantages of the province and offer stable and high-quality Russian language services. Now, Heilongjiang Province has positioned itself as a window for China, thus providing opportunities for the revitalization and development of Heilongjiang Province. The Russian language and its services are good intermediaries to create "dialogue" between China and Russia as well as achieve a win-win community. Giving full play to the traditional advantage of the Russian language in the province, the Russian language service can be a "golden banner" for the province to promote its comprehensive competitive power.

\section{Funding}

The "13th Five-Year Plan" of Education Science Key Project of Heilongjiang Province in 2020 (Project Number: GJB1320294).

\section{Disclosure statement}

The author declares that there is no conflict of interest.

\section{References}

[1] Russell, 1983, Human Knowledge [Zhang J, Trans.], The Commercial Press, Beijing, 68. 
[2] Gadamer, 2019, Hermeneutics I Truth and Method [Hong H, Trans.], The Commercial Press, Beijing, Preface XV.

[3] He W, 2000, Hermeneutics and Ethics - On the Core of Gadamer's Philosophy of Practice. Philosophical Research, 4(12): 60-67, 77.

[4] Li L, Tomasello M, 2021, Moral Functions of Language. Social Cognition, 39(1): 99-116.

[5] Zhang L, Xue X, Li H, et al., 2019, The Germination and Development of Russian Education in Heilongjiang Province. Heihe Journal, 4(06): 102-104.

[6] Jiang D, 2011, Prospect of Russian Teaching in Middle Schools of Heilongjiang Province. Journal of Beijing Electric Power College, 4(4): 242-243.

[7] Jiang LJ, 2004, Research on the Development Direction of Russian Education in Heilongjiang Province. Heilongjiang Higher Education Research, 4(04): 109-111.

[8] Zhang T, Cao X, 2020, Review of Heilongjiang-Russia Trade Development in 40 Years of Reform and Opening-Up. Foreign Trade and Economics, 4(01): 58-62.

[9] Zhao Q, 2012, Current Situation and Countermeasures of Russian Teaching Reform in Middle Schools. Chinese Russian Teaching, 31(02): 88-91.

[10] Zhang X, Shan H, 2020, A Survey on The Attitude of College Students Majoring in Economics and Trade to Russian Language - A Case Study of Students Majoring in Economics and Trade in Heilongjiang Institute of Technology. Chinese and Foreign Entrepreneurs, 4(04): 203-204. 